Journal of Computer Science 8 (1): 159-162, 2012

ISSN 1549-3636

(C) 2012 Science Publications

\title{
The Effect of the Bone-Plate Whole Spacing on the Interfragmentary Strain
}

\author{
Boonthum Wongchai \\ Department of Mechanical Engineering, Faculty of Engineering at Si Racha, \\ Kasetsart University, 199 M.6, Tungsukhla, Si Racha, Chonburi, 20230, Thailand
}

\begin{abstract}
Problem statement: The bone plate is commonly used when human bone fracture occurs. The Inter Fragmentary (IFS) is an important factor for curing human bone fracture and designing the bone plate. The best IFS range from 2-10\%.The whole spacing is a factor affecting the IFS that should be taken into account. Approach: This research propose a study on the effect of the whole spacing on the IFS. Two directions of the whole spacing are defined in the axial direction of the bone plate and the transverse direction of the bone plate. The Finite Element Method is used to investigate the IFS. Results: The experimental results show that the value of the IFS is between 2 and 10\%. The IFS increases when the whole spacing in the axial direction and the transverse direction are increased. In other words, decreasing of the number of holes has the same results as increasing the whole spacing in the axial direction. Conclusion: The varying holes spacing and the different numbers of holes cause the distinguished IFS.
\end{abstract}

Key words: Inter fragmentary strain, whole spacing, bone plate, finite element, human bone, fracture occurs, IFS range, Inter Fragmentary (IFS), Locking Compression Plate (LCP)

\section{INTRODUCTION}

The human long bone fractures (femur fracture and tibia fracture) occur frequently. When the body weight transmits to the femur and the tibia, the maximum bending moments occur at the middle points of the femur and the tibia. These are the critical points of the bone fracture (Saffar et al., 2009).

The bone plate is commonly used when a human bone fracture occurs. There are various types of the bone plate, the Dynamic Compression Plate (DCP), the Limited-Contact Dynamic Compression Plate (LC-DCP), the Locking Compression Plate (LCP) and etc. The DCP and the fractured bone are fixed by using a number of the conventional screws. The compression force between bone and plate is the main problem of the DCP (Kanchanomai et al., 2008; Field et al., 2004). The LCP is developed to solve this problem by using the locking head screws and the threaded holes (Miller et al., 2007; Stoffel et al., 2003).

There are a lot of researches that use the bone plate in rabbit to study the results or the side effects before using in human (Sharifi et al., 2009; Sadi et al., 2010).

The bone plate designs have been developed by using experimental and simulation. All design conditions propose to the lowest stress on the bone plate, including thickness of the bone plate, configuration of the screw fixation, the spacing between bone and plate, diameter of the screw, the modulus of elasticity of the bone plate and etc (Kim et al., 2010; Kanchanomai et al., 2008; Ahmad et al., 2007; Stoffel et al., 2003; Field et al., 1999; Benli et al., 2008; Fouad, 2010).
Another important factor is the Inter Fragmentary Strain (IFS). The IFS is defined as the ratio of the fracture gap displacement after the compressive load applied and the original fracture gap as show in Fig.1. The Eq. 1 of IFS is:

$\mathrm{IFS}=\frac{\Delta \mathrm{L}}{\mathrm{L}}$

Where:

$\Delta \mathrm{L}=$ Fracture gab displacement after the compressive load applied

$\mathrm{L}=$ Original fracture gap length.

The best IFS range from 2-10\% (Perren et al., 1979; Kim et al., 2010).

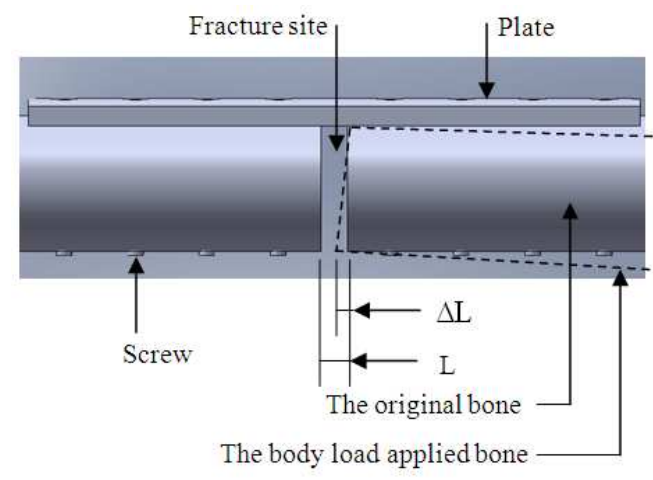

Fig 1: The deformation of the fractured bone 


\section{MATERIALS AND METHODS}

Finite Element Analysis (FEA): The bone model is modeled from the 3403-15 model of Pacific Research Laboratories, outer diameter of $35 \mathrm{~mm}$, cortical thickness of $4.3 \mathrm{~mm}$ and length of $500 \mathrm{~mm}$. The Pacific Research Laboratories bone models are usually used in biomechanics research (Viececonti et al., 2003; Mahmoud, 2001; Stoffel et al., 2003).

The models of bone, plate and screws are modeled in SolidWorks 2007. The bone is cut in half. A $6 \mathrm{~mm}$ gap is bridged with plate and screws. The whole spacing is designed by the variables $a$ and $b$ as shown in Fig. 2a, b.

Where:

$\mathrm{a}=$ Whole spacing in $\mathrm{x}$ direction

$\mathrm{b}=$ Whole spacing $\backslash$

$\mathrm{y}=$ Direction. The values of $\mathrm{a}$ and $\mathrm{b}$ are shown in Table 1.

All models are transformed into the finite element models by using MSC Software, MSC. Patran 2008r1 for pre/post processing and MD.

Nastran $\mathrm{r} 3 \mathrm{~b}$ for solution processing. The four-node tetrahedral element is used in the finite element models.

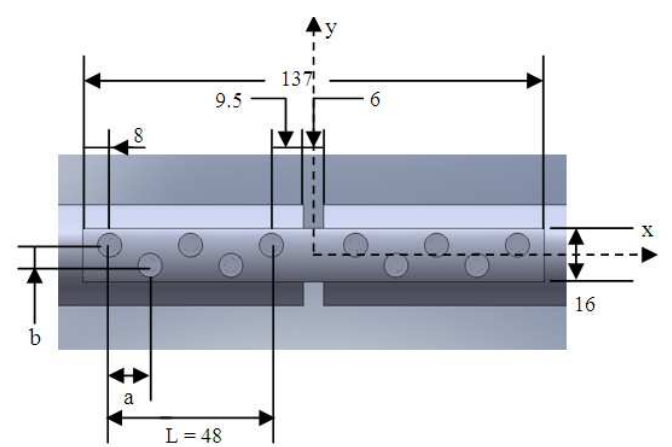

(a)

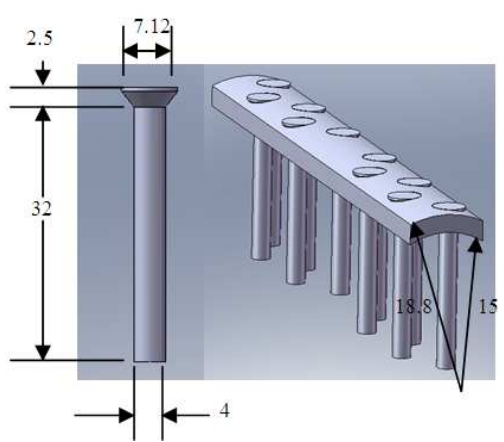

(b)

Fig. 2: (a) The variables of whole spacing ( $a$ and $b$ ) and the plate dimensions (b) the screw dimension (all dimensions are in $\mathrm{mm}$ )

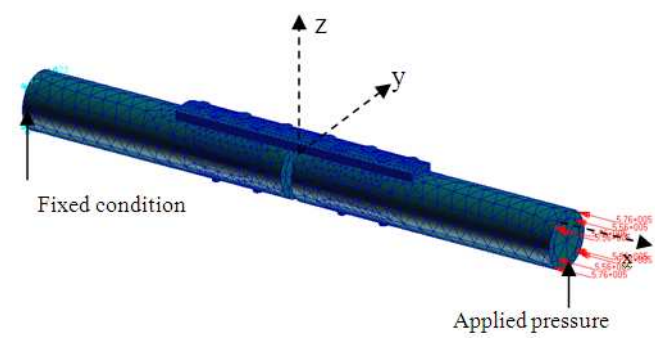

Fig. 3: The finite element model of the bone fractured, plate and screws

Table 1: The values of $\mathrm{a}$ and $\mathrm{b}$

\begin{tabular}{lllc}
\hline Model & $\mathrm{a}(\mathrm{mm})$ & $\mathrm{b}(\mathrm{mm})$ & Numbers of hole \\
\hline 1 & 16 & 0 & 8 \\
2 & 16 & 2 & 8 \\
3 & 16 & 4 & 8 \\
4 & 16 & 6 & 8 \\
5 & 12 & 0 & 10 \\
6 & 12 & 2 & 10 \\
7 & 12 & 4 & 10 \\
8 & 12 & 6 & 10 \\
9 & 9.6 & 0 & 12 \\
10 & 9.6 & 2 & 12 \\
11 & 9.6 & 4 & 12 \\
12 & 9.6 & 6 & 12 \\
\hline
\end{tabular}

Table 2: Material properties

\begin{tabular}{lrl}
\hline Young's modulus & $(\mathrm{GPa})$ & Poisson's ratio \\
\hline DCP & 193.0 & 0.3 \\
Screw & 193.0 & 0.3 \\
Cortical bone & 17.0 & 0.3 \\
Cancerous & 0.7 & 0.2 \\
\hline
\end{tabular}

The compression force of $200 \mathrm{~N}$ (Stoffel et al., 2003) is applied as the pressure on the cross section area of cortical bone and cancerous bone. The fixed condition is applied at another end of the bone as shown in Fig. 3.

The contact conditions are applied at the mated surfaces. The contact conditions of plate and screws, cortical bone and the cancerous bone, cortical bone and screws, cancerous bone and screws are the glue contact. While the contact condition of plate and cortical bone is the touch contact.

Materials: The DCP and screw are made of stainless steel. Material properties of the DCP, screw, cortical bone and cancerous bone are shown in Table 2 (Stoffel et al., 2003).

\section{RESULTS}

The displacement of bone fracture is shown in Fig. 4. Point A and B are moved after compression load is applied. The displacement after applying the compressive load $(\Delta \mathrm{L})$ is the relative displacement between point $\mathrm{A}$ and point $\mathrm{B}$ 


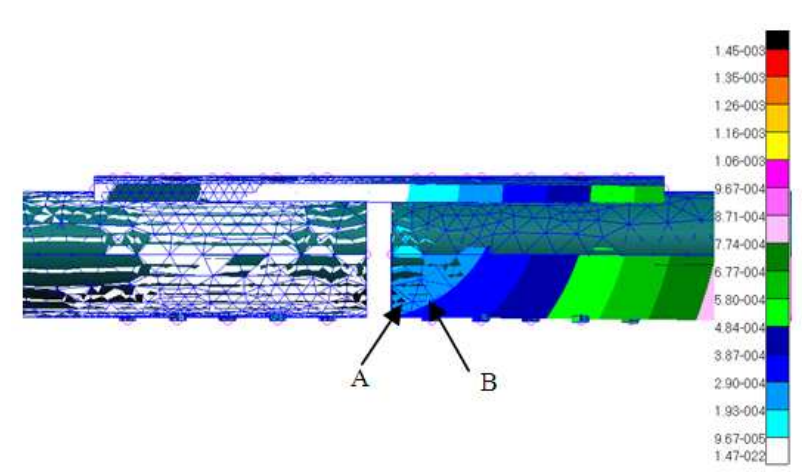

Fig. 4: The displacement of bone fracture

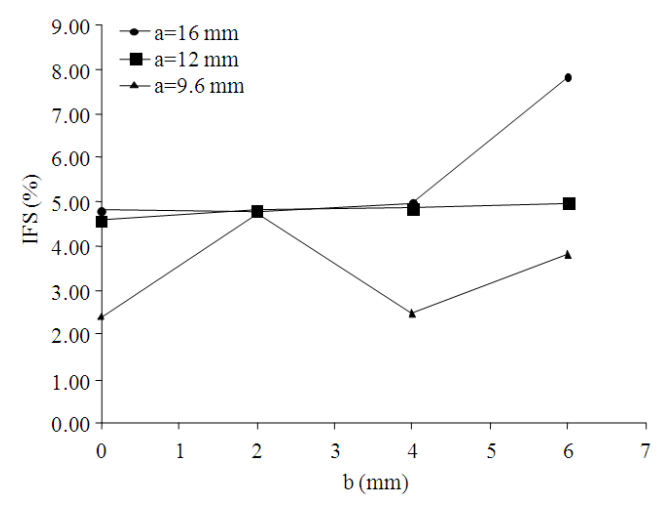

Fig. 5: The IFS when $a$ is fixed and $b$ is varied

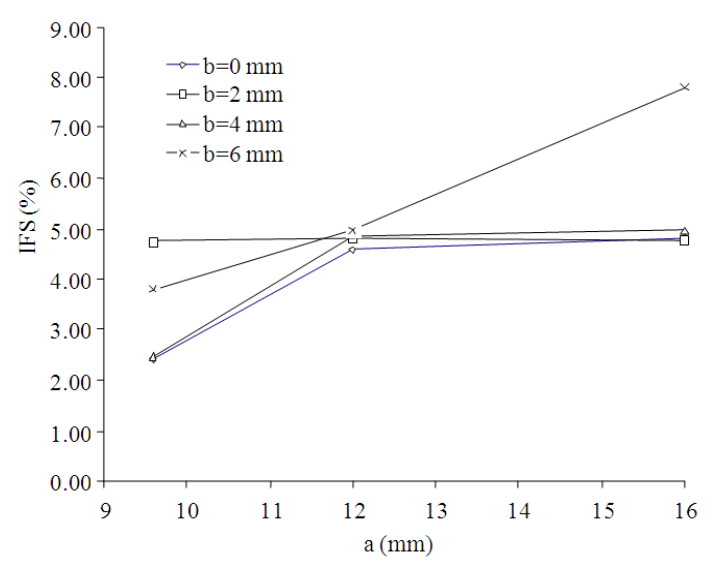

Fig. 6: The IFS when $b$ is fixed and a is varied

The values of the displacement after applying the compressive load $(\Delta \mathrm{L})$ are shown in Table 3.

The IFS are shown in Table 4 and 5. Table 4 shows the value of the IFS when (a) is fixed and (b) is varied. On the other way, Table 5 shows the value of the IFS when (b) is fixed and (a) is varied.

From Table 4 and 5 we can plot the graphs of the IFS, (a) and (b) as shown in Fig. 5 and 6.
Table 3: The displacement after the compressive load is applied $(\Delta \mathrm{L})$

\begin{tabular}{ll}
\hline Model & $\Delta \mathrm{L}(\mathrm{mm})$ \\
\hline 1 & 0.289 \\
2 & 0.287 \\
3 & 0.298 \\
4 & 0.469 \\
5 & 0.200 \\
6 & 0.288 \\
7 & 0.292 \\
8 & 0.299 \\
9 & 0.145 \\
10 & 0.286 \\
11 & 0.149 \\
12 & 0.229 \\
\hline
\end{tabular}

Table 4: The IFS when $a$ is fixed and $b$ is varied

\begin{tabular}{llll}
\hline Model & $\mathrm{a}$ & $\mathrm{b}$ & IFS (\%) \\
\hline 1 & 16 & 0 & 4.82 \\
2 & 16 & 2 & 4.78 \\
3 & 16 & 4 & 4.97 \\
4 & 16 & 6 & 7.82 \\
5 & 12 & 0 & 4.58 \\
6 & 12 & 2 & 4.80 \\
7 & 12 & 4 & 4.87 \\
8 & 12 & 6 & 4.98 \\
9 & 9.6 & 0 & 2.42 \\
10 & 9.6 & 2 & 4.77 \\
11 & 9.6 & 4 & 2.48 \\
12 & 9.6 & 6 & 3.82 \\
\hline
\end{tabular}

Table 5: The IFS when $b$ is fixed and $a$ is varied

\begin{tabular}{llll}
\hline Model & $\mathrm{a}$ & $\mathrm{b}$ & IFS $(\%)$ \\
\hline 1 & 16 & 0 & 4.82 \\
5 & 12 & 0 & 4.58 \\
9 & 9.6 & 0 & 2.42 \\
2 & 16 & 2 & 4.78 \\
6 & 12 & 2 & 4.80 \\
10 & 9.6 & 2 & 4.77 \\
3 & 16 & 4 & 4.97 \\
7 & 12 & 4 & 4.87 \\
11 & 9.6 & 4 & 2.48 \\
4 & 16 & 6 & 7.82 \\
8 & 12 & 6 & 4.98 \\
12 & 9.6 & 6 & 3.82 \\
\hline
\end{tabular}

\section{DISCUSSION}

The result from Fig. 5 and 6 show that the IFS increases when the whole spacing in the axial direction of the bone plate ( $x$ direction) and the transverse direction of the bone plate (y direction) are increased because the number of holes on plate is $\frac{\mathrm{L}}{\mathrm{a}}+1$ we can proof that the IFS increases when the number of holes is increased.

\section{CONCLUSION}

The varying holes spacing and the different number of holes causes the distinguished IFS. 


\section{REFERENCES}

Ahmad, M., R. Nanda, A.S. Bajwa, J.C. Couto and S. Green et al., 2007. Biomechanical testing of the locking compression plate: When does the distance between bone and implant significantly reduce construct stability? Injury, 38: 358-364.

Benli, S., S., Aksoy, H., Havitcioglu and M., Kucuk, 2008. Evaluation of bone plate with low-stiffness material in terms of stress distribution. J. Biomechanics, 41: 3229-3235. DOI: 10.1016/j.jbiomech.2008.08.003

Field, J.R., H. Tornkvist, T.C. Hearn, G.S. Smith and T.D. Woodside, 1999. The influence of screw omission on construction stiffness and bone surface strain in the application of bone plates to cadaveric bone. Injury, 30: 591-598.

Field, J.R., R.E. Wilson and R.M. Stanley, 2004. An evaluation of interface contact profiles in two low contact bone plates. Injury, 35: 551-556. DOI: 10.1016/S0020-1383(03)00215-8

Fouad, H., 2010. Assessment of function-graded materials as fracture fixation bone-plates under combined loading conditions using finite element modelling. Med. Eng. Phys., 33: 456-463.

Kanchanomai, C., V. Phiphobmongkol and P. Muanjn, 2008. Fatigue failure of an orthopedic implant-A locking compression plate. Eng. Failure Anal., 15: 521-530. DOI: 10.1016/j.engfailanal.2007.04.001

Kim, S.H., S.H. Chang and H.J. Jung, 2010. The finite element analysis of a fractured tibia applied by composite bone plates considering contact conditions and time-varying properties of curing tissues. Composite Struct., 92: 293-2118. DOI: 10.1016/j.compstruct.2009.09.051
Mahmoud, A.H., 2001. Solid Model in IGES Format. Department of Clinical Sciences.

Miller, D.L. and T. Goswami, 2007. A review of locking compression plate biomechanics and their advantages as internal fixators in fracture healing. Clin. Biomech., 22: 1049-1062. DOI: 10.1016/j.clinbiomech.2007.08.004

Perren, S.M., 1979. Physical and biological aspects of fracture healing with special reference to internal fixation. Clin. Orthopeadics Related Res., 138: 175-196.

Sadi, F., A. Veshkini, D. Sharifi and M.N. Masouleh, 2010. Ultrasonography and radiography evaluation of the cartilage graft in repair of experimentally induced radial bone defect in rabbit. Am. J. Anim. Vet. Sci., 5: 40-44.

Saffar, K.P., N.J. Pour and S.M. Rajaai, 2009. How does the bone shaft geometry affect its bending properties? Am. J. Applied Sci., 6: 463-470.

Sharifi, D., S., Soroori, S., Hasaraki and N., Jafari, 2009. Radiographic evaluations of the tetracalcium phosphate and diacalcium phosphate with bone plate in osseo-integration of bone repair in rabbit. Am. J. Anim. Vet. Sci., 4: 80-84. DOI: 10.3844/ajavsp.2009.80.84

Stoffel, K., U. Dieter, G. Stachowiak, A. Gachter and M. Kuster, 2003. Biomechanical testing of the LCP -how can stability in locked internal fixators be controlled? Injury, 34: 11-19. DOI: 10.1016/j.injury.2003.09.021 